\title{
Distribution of Serotypes, Antimicrobial Resistance and Virulence Genes among Streptococcus agalactiae Isolated from Bovine in China
}

\author{
Zhe Zhang, Feng Yang, Xin-pu Li, Jin-yin Luo, Long-hai Liu, Dan Wang, Ya-ru Zhang \& Hong-sheng Li
}

\begin{abstract}
Background: Bovine mastitis, a global disease that is responsible for large economic losses each year due to lower milk yield and reduced milk quality. In some countries, especially in China, Streptococcus agalactiae has become one of the most frequently detected pathogen. Antibiotic treatment and vaccine immunization are important strategies for the control of infectious diseases. The main objective of the present study was to evaluate distribution of bovine mastitis pathogens and antimicrobial resistance of S. agalactiae, and contribute to the treatment of bovine mastitis.

Materials, Methods \& Results: Clinical mastitis samples $(\mathrm{n}=1,122)$ were collected from 27 dairy farms located in 15 different provinces of China during 2012-2018. The pathogens were identified by $16 \mathrm{~S}$ rDNA method. Antimicrobial susceptibility was assessed by disc diffusion method. Molecular characteristics was distinguished based on PCR. The results showed that the main pathogens were Streptococcus agalactiae $(\mathrm{n}=324,26.2 \%)$, Escherichia coli $(\mathrm{n}=287,23.2 \%)$, and Staphylococcus aureus $(\mathrm{n}=131,10.6 \%)$. The serotypes of Streptococcus agalactiae were serotype II (53.6\%), Ia (44 \%) and VII (1.2\%), respectively. Streptococcus agalactiae were resistant to kanamycin (93.8\%), gentamicin (49.4\%), vancomycin $(49.4 \%)$, tetracycline $(35.8 \%)$, clindamycin $(34.6 \%)$ and erythromycin $(32.1 \%)$. The main resistance genes were ermA $(53.1 \%)$ and ermB $(85.2 \%)$. Resistance to erythromycin was attributed to the genes ermA $(P<0.05)$ and resistance to tetracycline was attributed to the genes $t e t K$, tetM, tet $O(P<0.01)$. The virulence genes $\operatorname{scp} B(81.4 \%), \operatorname{cyl}(100 \%), \operatorname{gln} A$ (76.6\%), $c f b$ (98.8\%), hylB (98.8\%), scaA (69.1\%) were detected in almost all isolates.

Discussion: In the present study, Streptococcus agalactiae, Escherichia coli and Staphylococcus aureus were the pathogens isolated most frequently from clinical mastitis. In the case of $S$. agalactiae, we performed capsular serotyping of isolates. As a result, serotype II (53.6\%), Ia (44\%) and VII (1.2\%) were detected which revealed variation in the distinct geographical areas. We found that serotypes (Ia and II) and $\beta$-hemolytic have significant correlation $(P<0.01)$ in all isolated strains. We made an assumption that either in processes of capsular and haemolytic appearance effected the expression of another. The unclear mechanism remains to be resolved in the future. Penicillin was recommended as a preferred antibiotic for the treatment of both human and bovine $S$. agalactiae infection. In the present study, resistance to erythromycin and clindamycin were observed in $32 \%$ and $34.6 \%$ of our strains, respectively. The results indicated that the ermB gene was most frequent among the erythromycin-resistant $S$. agalactiae. However, we found that the susceptibility to erythromycin and gene ermA have a significant interaction, while susceptibility to erythromycin and gene ermB have a not significant interaction by analyzing the relationship of phenotypic and genotypic resistance. The severity of $S$. agalactiae infections may be determined by various virulence factors. Surface enzyme ScpB, a C5a peptidase, encode by $s c p B$ gene, could promote bacterial invasion of epithelial cells by attenuating recruitment of polymorphonuclear leukocytes to the site of infection. In the present study, the $s c p B$ gene was found in $81.4 \%$ of all strains. The results suggested the $c y l, c f b, h y l B$ and $s c p B$ genes may play an important role in the virulence of Streptococcus agalactiae pathogens.
\end{abstract}

Keywords: Streptococcus agalactiae, serotypes, antimicrobial resistance, virulence genes.

DOI: $10.22456 / 1679-9216.97254$ 


\section{INTRODUCTION}

Bovine mastitis, a global disease that is responsible for large economic losses each year due to lower milk yield and reduced milk quality $[6,15,17,32]$. Mastitis is complex, developing as a result of interaction between various factors associated with the host, specific pathogens, environment, and management $[1,36]$. Over 150 different bacteria have been recorded to cause bovine mastitis [5,20,33]. In China, Streptococcus agalactiae has become one of the most frequently detected pathogens $[27,35,36]$.

Bacterial genotyping is one of the key steps in the development of an effective and practical vaccine. Capsular serotyping is a classical method used for S. agalactiae $[4,18]$. It is common knowledge that antibiotics are among the major tools in combating bovine mastitis. However, due to the widespread use of antimicrobial compounds, the occurrence of antimicrobial-resistant has increased [7,25]. Resistance genes are responsible for resistance to erythromycin and tetracycline which included ermA, ermB, erm C, mefA, tet $K$, tet L, tetM, tet $O$ and $t e t S$, respectively $[7,9,11]$. The ability of infections may be determined by various virulence genes, such as $c y l, c f b, h y l B, s c p B, l m b, b a c$, and $s c a A$, which encodes for $\beta$-hemolysin, Christie-Atkins-Munch-Peterson (CAMP), hyaluronidase, surface enzyme ScpB (C5a peptidase), laminine-binding protein, $\beta$-antigen, aggregation factor, respectively $[3,19]$.

The aim of the present study was to evaluate distribution of bovine mastitis pathogens, antimicrobial resistance and virulence genes of Streptococcus agalactiae isolated from bovine mastitis cases in China, and contribute to the treatment of bovine mastitis.

\section{MATERIALS AND METHODS}

\section{Sample collection}

A total of 1,122 milk samples were collected from 27 commercial dairy farms located in 15 different provinces of China from 2012 to 2018. All samples were collected from cows with clinical mastitis aseptically as described by Pitkälä et al. [29]. Before sampling, first stream of milk were discarded, and the teat ends were disinfected with cotton swabs soaked in $70 \%(\mathrm{v} / \mathrm{v})$ alcohol and allowed to dry. Then 5-mL secretion was collected into a sterile $10-\mathrm{mL}$ tube. All samples were kept at $4^{\circ} \mathrm{C}$ for microbiological examination within $18 \mathrm{~h}$.

\section{Bacterial isolation and identification}

The samples were enriched in $2 \mathrm{~mL}$ nutrient broth supplemented with $1 \%$ glucose (w/v) and $2 \%$ calf serum, and incubated at $37^{\circ} \mathrm{C}$ for $18-24 \mathrm{~h}$. A bacteriological loop was used to spread approximately $0.02 \mathrm{~mL}$ of each enriched bacteria samples on blood agar ${ }^{1}$. The plates were incubated at $37^{\circ} \mathrm{C}$ and examined after 24 h. Typical Streptococcus colonies were distinguished microscopically by colony morphology, then by the characteristic appearance on hemolysis, and Gram's stain, catalase test and CAMP test, respectively.

The genomic DNA of strains was extracted from overnight cultured isolates using the Bacterial DNA Kit ${ }^{2}$. The purified genomic DNA was stored at $-20^{\circ} \mathrm{C}$ until use. The $16 \mathrm{~S}$ rDNA sequence was amplified by Takara $16 \mathrm{~S}$ rDNA Bacterial Identification PCR Kit ${ }^{3}$. The PCR products were analyzed by electrophoresis using 1\% agarose gel. By comparing the Biotechnology Information (NCBI), bacterial species were identified.

\section{Hemolytic characteristic and capsular serotypes}

Strains of Streptococcus agalactiae $(\mathrm{n}=81)$ were randomly selected for serotyping, antimicrobial susceptibility test and antimicrobial resistance and virulence genes detection. For hemolytic characteristics of $S$. agalactiae strains, isolates were cultured on blood agar plates. Identification of serotypes was performed by multiplex PCR assay as described previously [18].

\section{Antimicrobial susceptibility testing}

The antimicrobial susceptibility testing was performed by disc diffusion method on Muller-Hinton agar plates supplemented with 5\% defibrinated sheep blood $^{4}$ according to the Clinical Laboratory Standards Institute (CLSI). The antimicrobial drug discs included penicillin $\mathrm{G}$ ( $\beta$-lactam), gentamicin (aminoglycoside), tetracycline (tetracycline), erythromycin (macrolide), kanamycin (aminoglycoside) clindamycin (lincosamide), vancomycin (glycopeptide), chloramphenicol (amphenicol), ofloxacin (fluoroquinolone) and ciprofloxacin (fluoroquinolone). After incubation at $37^{\circ} \mathrm{C}$ for 18-24 h, the strains could be determined as sensitive, intermediate (reduced susceptibility) or resistant characteristic by measuring the zone of inhibition according to the CLSI guidelines. We also determined the antimicrobial susceptibility of $\beta$-hemolytic and non- $\beta$-hemolytic Streptococcus agalactiae strains according to Clinical and Laboratory Standards Institute (CLSI 2014). 
Detection of antimicrobial resistance genes and virulence genes

The antimicrobial resistance and virulence genes of strains were detected by conventional PCR as described previously $[2,7,16]$. The primers used for PCR amplification and sequence were shown in supplementary material.

\section{Statistical analysis}

SPSS 21.0 was used to analyze the associations between phenotypic and genotypic resistance patterns. The intermediate isolates were considered to be resistant.

\section{RESULTS}

\section{Species identification}

Out of 1,122 clinical mastitis milk samples collected and processed, $87.4 \%(\mathrm{n}=981)$ were culture positive for bacteria. A total of 1,235 bacterial isolates were obtained and the distribution of bacterial species was shown in Table 1.

Table 1. The distribution of bacterial and fungal species.

\begin{tabular}{|c|c|c|}
\hline Pathogen & Number & Proportion (\%) \\
\hline Streptococcus agalactiae & 324 & 26.2 \\
\hline Escherichia coli & 287 & 23.2 \\
\hline Staphylococcus aureus & 131 & 10.6 \\
\hline Staphylococcus epidermidis & 95 & 7.7 \\
\hline Streptococcus lactis & 80 & 6.5 \\
\hline Enterococcus faecalis & 78 & 6.3 \\
\hline Streptococcus uberis & 52 & 4.2 \\
\hline Enterococcus faecium & 47 & 3.8 \\
\hline Streptococcus dysgalactiae & 19 & 1.5 \\
\hline Klebsiella sp. & 18 & 1.5 \\
\hline Lactococcus lactis subsp. & 15 & 1.2 \\
\hline Pseudomonas aeruginosa & 7 & 0.6 \\
\hline Moulds & 7 & 0.6 \\
\hline Streptococcus parauberis & 6 & 0.5 \\
\hline Shigella & 6 & 0.5 \\
\hline Lactococcus garvieae & 5 & 0.4 \\
\hline Yeasts & 5 & 0.4 \\
\hline Citrobacter & 5 & 0.4 \\
\hline Streptococcus pyogenes & 4 & 0.3 \\
\hline Acinetobacter sp. & 3 & 0.2 \\
\hline Arcanobacterium pyogenes & 2 & 0.2 \\
\hline Proteus sp. & 2 & 0.2 \\
\hline Undetected & 37 & 3.0 \\
\hline Total & 1235 & 100 \\
\hline
\end{tabular}

Hemolytic characteristic and capsular serotypes

From the 81 isolates analyzed, only three serotypes were identified: Ia (44\%), II (53.6\%) and VII $(1.2 \%)$ as shown in Table 2 . In addition, we found that the serotypes (Ia and II) and $\beta$-hemolytic have a significant correlation $(P<0.01)$ by Chi-square analysis.

Table 2. The result of serotypes and hemolysis of Streptococcus agalactiae.

\begin{tabular}{cccc}
\hline \multirow{2}{*}{ Serotype } & \multicolumn{2}{c}{ The type of hemolytic } & \multirow{2}{*}{ Total } \\
\cline { 2 - 3 } & $\beta$-hemolytic & Non- $\beta$-hemolytic & \\
\hline Ia & 40 & 1 & 41 \\
II & 2 & 37 & 39 \\
VII & 1 & 0 & 1 \\
\hline Total & 43 & 38 & 81 \\
\hline
\end{tabular}

Antimicrobial susceptibility

The antimicrobial resistances of Streptococcus agalactiae cultured from bovine mastitis were shown in Table 3. Most of them were resistant to kanamycin (93.8\%). In addition, we found that $96.3 \%$ of strains were resistant to at least one of the antibiotics tested.

\section{Detection of antimicrobial resistance genes}

The presence of antibiotic resistance genes was studied by PCR in all Streptococcus agalactiae strains as shown in Table 4. The relationship between the antimicrobial resistance and corresponding genes were also analysed in this study. As show in Table 5, we found the susceptibility to erythromycin and gene ermA have a significant interaction $(P<0.05)$, the susceptibility to tetracycline and tet $K$, tet $M$, tet $O$ have a strongly significant interaction $(P<0.01)$.

Detection of virulence-related genes

The presence of nine virulence-related genes was tested by PCR. The gene $c y l$ was present in all Streptococcus agalactiae isolates. The incidence of $c f b, h y l B, s c p B, g \ln A, s c a A$ were $98.8 \%, 98.8 \%, 81.4 \%$, $76.6 \%$ and $69.1 \%$, respectively.

\section{DISCUSSION}

\section{Isolation and identification of mastitis pathogens}

Pathogens as a cause of mastitis have become the major concern to the dairy industry worldwide due to huge economic losses. In the present study, Streptococcus agalactiae, Escherichia coli and Staphylococcus aureus 
Z. Zhang, F. Yang, X. Li, et al. 2019. Distribution of Serotypes, Antimicrobial Resistance and Virulence Genes among Streptococcus agalactiae Isolated from Bovine in China.

Table 3. Antimicrobial susceptibility of Streptococcus agalactiae.

\begin{tabular}{ccccccc}
\hline & \multicolumn{7}{c}{ Antimicrobial susceptibility } & & $\mathrm{S}^{*}$ \\
\cline { 2 - 7 } Antimicrobial agent & \multicolumn{2}{c}{$\mathrm{R}^{*}$} & & $\mathrm{I}^{*}$ & $\mathrm{n}$ & $\%$ \\
\cline { 2 - 7 } & $\mathrm{n}$ & $\%$ & 0 & 0 & 81 & 100 \\
Penicillin & 0 & 0 & 4 & 4.9 & 1 & 1.2 \\
Kanamycin & 76 & 93.8 & 29 & 35.8 & 12 & 14.8 \\
Gentamicin & 40 & 49.4 & 10 & 12.3 & 67 & 82.7 \\
Ofloxacin & 4 & 4.9 & 27 & 33.3 & 45 & 55.6 \\
Ciprofloxacin & 9 & 11.1 & 15 & 18.5 & 62 & 76.5 \\
Chloramphenicol & 4 & 4.9 & 2 & 2.5 & 53 & 65.4 \\
Erythromycin & 26 & 32.1 & 10 & 12.3 & 42 & 51.9 \\
Tetracycline & 29 & 35.8 & 0 & 0 & 53 & 65.4 \\
Clindamycin & 28 & 34.6 & 0 & 0 & 41 & 50.6 \\
Vancomycin & 40 & 49.4 & & & & \\
\hline
\end{tabular}

${ }^{*}$ R: resistant; I: intermediate; S: sensitive. The same as below.

Table 4. Distribution of antibiotic-resistance genes among Streptococcus agalactiae.

\begin{tabular}{ccc}
\hline Target gene & The number of strains with target gene & percentage \\
\hline ermA & 43 & $53.1 \%$ \\
ermB & 69 & $85.2 \%$ \\
ermC & 3 & $3.7 \%$ \\
mefA & 0 & $0 \%$ \\
tetK & 32 & $39.5 \%$ \\
tetL & 0 & $0 \%$ \\
tetM & 24 & $29.6 \%$ \\
tetO & 24 & $29.6 \%$ \\
tetS & 32 & $39.5 \%$ \\
\hline
\end{tabular}

Table 5. Comparison of phenotypic and genotypic test for antimicrobial resistance.

\begin{tabular}{|c|c|c|c|c|c|c|c|}
\hline \multirow{2}{*}{ Antimicrobials } & \multirow{2}{*}{ Gene(s) } & \multicolumn{5}{|c|}{ Characteristics of Streptococcus agalactiae* } & \multirow{2}{*}{$P$ value } \\
\hline & & $\mathrm{P}+/ \mathrm{G}+(\mathrm{n})$ & $\mathrm{P}-/ \mathrm{G}-(\mathrm{n})$ & $\mathrm{P}+/ \mathrm{G}-(\mathrm{n})$ & $\mathrm{P}-/ \mathrm{G}+(\mathrm{n})$ & $\mathrm{G}+(\%)$ & \\
\hline \multirow{4}{*}{ Erythromycin } & ermA & 20 & 22 & 23 & 6 & $79.2 \%$ & 0.032 \\
\hline & ermB & 24 & 10 & 45 & 2 & $94.3 \%$ & 0.214 \\
\hline & ermC & 1 & 53 & 2 & 25 & $1.9 \%$ & 0.963 \\
\hline & mefA & 0 & 26 & 0 & 55 & 0 & -- \\
\hline \multirow{5}{*}{ Tetracycline } & tetK & 20 & 41 & 12 & 9 & $69.0 \%$ & $<0.001$ \\
\hline & tetL & 0 & 53 & 0 & 29 & 0 & -- \\
\hline & tetM & 22 & 51 & 2 & 7 & $75.9 \%$ & $<0.001$ \\
\hline & tetO & 18 & 47 & 6 & 11 & $62.1 \%$ & $<0.001$ \\
\hline & tetS & 12 & 33 & 20 & 27 & $41.4 \%$ & 0.797 \\
\hline
\end{tabular}




were the pathogens isolated most frequently from clinical mastitis. The same results were shown in previous reports [20,33,35]. Zhang et al. [36] observed that $S$. agalactiae was the bacterium isolated most frequently $(38.6 \%)$ from milk samples of mastitis cases in China, the result was similar with our date (26.2\%). In some other countries, the isolation rate of $S$. agalactiae has been reported to be $60 \%$ in Brazil and $42 \%$ in Colombia $[8,23]$, while lower isolation rate was found in Danish $(7 \%)$ and Ragusa (2\%) [14,21]. In this study, the proportions of E. coli and S. aureus were $23.3 \%$ and $10.6 \%$, respectively. The same results were shown in an Estonia study, where E. coli $(15.9 \%)$ and S. aureus $(11.7 \%)$ were the pathogens isolated most commonly from case of clinical mastitis $[21,26]$. However, the results were different to previous reports where $E$. coli $(7 \%)$ and S. aureus (74\%) [20]. The prevalence of dominant mastitis pathogens differs considerably among countries. Even in the same country, it is always different among regions due to different management level and climate.

\section{Capsular serotypes and haemolytic characteristic}

In the case of Streptococcus agalactiae, we performed additional molecular serotyping of the isolated strains. Such investigations are extremely important considering both epidemiology and prophylaxis, as they may aid the development of multivalent vaccines containing capsular polysaccharides [35]. Several methods have been used to investigate the serotyping of $S$. agalactiae. Among them, capsular serotyping is a classical method used for $S$. agalactiae in epidemiological studies. To date, ten serotypes, based on the $S$. agalactiae capsular polysaccharides (cps), have been identified, including Ia, Ib, II-VIII and a new serotype IX $[4,18]$. In the present study, serotype II $(53.6 \%)$, Ia (44\%) and VII (1.2\%) were detected from S. agalactiae strains isolated from clinical cows with mastitis [35], our finding are coincident with the previously reported data, but the prevalence of the each serotype was variable and we also identified one serotype VII. Indeed, the data of serotype distribution of $S$. agalactiae associated with bovine mastitis have revealed considerable variation in the distinct geographical areas. Serotype Ia, $\square, \square$, IV and $\mathrm{V}$ reported previously were the most prevalent in the Brazil, Canada and Norway, respectively [28,30,37].

In the present study, we also identified haemolytic characteristic of all S. agalactiae strains. We concluded that serotypes (Ia and II) and $\beta$-hemolytic have significant correlation $(P<0.01)$ in all isolated strains. We made an assumption that either in processes of capsular and haemolytic appearance effected the expression of another. The unclear mechanism remains to be resolved in the future.

\section{Phenotypic and genotypic resistance}

The present study showed that 81 Streptococcus agalactiae isolates tested against 10 antibiotics demonstrated the existence of a variable and broad antimicrobial resistance profile among local $S$. agalactiae. Penicillin was recommended as a preferred antibiotic for the treatment of both human and bovine S. agalactiae infection. Our data showed that all strains were susceptibility to penicillin which was in agreement with the previously reported data about the high levels of susceptibility to penicillin of mastitis $S$. agalactiae [12,24,31]. But one study from Inner Mongolia, China, reported penicillin resistant $S$. agalactiae, despite of decreased susceptibility to penicillin, it is still a preferred antibiotic used for treatment of $S$. agalactiae mastitis in China [7].

Erythromycin and clindamycin are recommended for penicillin-allergic individuals. However, because of extensive use of erythromycin and clindamycin, the rate of strains which were resistant to erythromycin have been described in Brazil from $10.5 \%$ between 1987 and 1988 to $60 \%$ between 2003 and 2006 [28]. In the present study, resistance to erythromycin and clindamycin were observed in $32 \%$ and $34.6 \%$ of our strains, respectively. This result is lower than those reported in Inner Mongolia, China [7].

Erythromycin and clindamycin belong to antimicrobial categories of macrolides and lincosamides, respectively. The products of erm genes confer combined resistance to macrolides and lincosamides by methylation of the ribosomal binding site of these drugs $[4,11]$ and the mef gene is another major resistant factor of resistance to erythromycin. We detected the related genes ermA (53.1\%), ermB (85.2\%), ermC $(3.7 \%)$ in all strains, while the strains of resistance to erythromycin harbored genes ermA (79.2\%), ermB $(94.3 \%)$, ermC $(1.9 \%)$, respectively. None of the tested strains were positive for mefA. The results indicated that the $\operatorname{erm} B$ gene was most frequent among the erythromycin-resistant $S$. agalactiae, which is in accordance with other studies [11,28]. However, we found that the susceptibility to erythromycin and gene ermA have a significant interaction, while susceptibility 
to erythromycin and gene $\mathrm{erm} B$ have a not significant interaction by analyzing the relationship of phenotypic and genotypic resistance.

Tetracycline is one of the main antimicrobials in the prevention and control of bovine mastitis $[22,34]$. Because of the vast and irrational use of tetracycline, the rate of tetracycline-resistant strains has been increased. Some reports have showed that the rate of tetracycline-resistant $S$. agalactiae from cattle was considerably higher than previous data in Brazil and in the United States [28]. Our result showed that the rate of tetracycline-resistant strains was $35.8 \%$, which was much lower than described $(61.7 \%)$ previously in Inner Mongolia, China [7]. Resistance to tetracycline is usually mediated either by active efflux of tetracycline from the cell (tet $L$ and $t e t K$ ) or by ribosomal protection (tetM, tet $O$, tet $S$, and tet $T$ ) from the action of tetracycline. In this present study, the genes tet $K$, tet $M$, tet $O$ and tetS were harbored in $39.5 \%, 29.6 \%, 29.6 \%$ and $39.5 \%$ of all strains respectively, while no gene tet $L$ was detected. The tetracycline-resistant strains carried at least one tet gene. The result was in accordance with previous report [7]. After analyzing the susceptibility to tetracycline and genes tet, the result indicated resistance to tetracycline was attributed to the genes tet $K$, tet $M$ or $\operatorname{tet} O(P<0.01)$ which are in according to previous study of Staphylococcus aureus [35].

In this study, all strains had a high frequency of phenotypic resistance to kanamycin $(98.8 \%)$ and gentamicin $(85.2 \%)$, which belonged to aminoglycosides. The rate of non-sensitive isolates from the mastitis milk of dairy cows were $54.8 \%$ (kanamycin) and $16.1 \%$ (gentamicin) in Shahrekord district, Iran [9]. In another study the rate of gentamicin-non-sensitive Streptococcus agalactiae isolates from bovine mastitis cases was $76.9 \%$ in Michigan [12]. In the contrast, the percentage of the gentamicin-resistance isolates from cases of bovine subclinical mastitis was found in $3.7 \%$ in India [19].

In addition, phenotypic resistance to partial pairs antibiotic agents have significant interaction. Excepting the antibiotic agents belonged to the same categories or antibiotic agents had the same resistant mechanisms, the mechanisms need to further study in the pairs antibiotic agents with significant interaction.

\section{Virulence genes}

The severity of Streptococcus agalactiae infections may be determined by various virulence factors.
Surface enzyme ScpB, a C5a peptidase, encode by $s c p B$ gene, could promote bacterial invasion of epithelial cells by attenuating recruitment of polymorphonuclear leukocytes to the site of infection $[3,19]$. In the present study, the $s c p B$ gene was found in $81.4 \%$ of all strains. The result was similar to the previous reported strains from human in Kuwait [10], while lower prevalence data was found in bovine strains in India and in Inner Mongolia, China [16,35]. Some reports showed the gene $s c p B$ was found more frequent in human than in bovine [10]. However, our result was not in accordance with these findings. The gene $c f b$ encodes forceramide-binding protein. According to the studies of Shome et al. [33], all $S$. agalactiae isolates carried the $c f b$ gene, the result was similar with our date. The genes $c y l$ and $h y l B$ encode for b-hemolysin and group B Streptococcal hyaluronate lyase, respectively. In the present study, $100 \%$ isolates had the $c y l$ gene, $98.8 \%$ isolates had the $h y l B$ gene. Ding et al. [7] reported that $c y l$ and $h y l B$ were founded to be $48.1 \%$ and $49.4 \%$, while Eskandarian et al. [13] reported that $c y l E$ and $h y l B$ were found in $97.1 \%$ and $94.2 \%$ in human strains, respectively. The gene $l m b, b a c$, and $b c a$ code laminin binding protein, $\beta$-C protein, $\alpha-\mathrm{C}$ protein respectively. Our result showed $24.7 \%, 12.3 \%, 49.3 \%$ strains of all harbored lmb, bac, and $b c a$, respectively. These observations are in agreement with earlier reports [7]. The results suggested the $c y l, c f b, h y l B$ and $s c p B$ genes may play an important role in the virulence of $S$. agalactiae pathogens.

\section{CONCLUSIONS}

This study showed that a relatively high number of isolates of Streptococcus agalactiae was cultured from milk samples of bovine clinical mastitis in China. The serotype a and serotype were the predominant serotypes in the $S$. agalactiae strains isolated from cases of bovine mastitis. The serotype distribution of the $S$. agalactiae strains could provide the basis for developing the bovine mastitis vaccine. Besides, our study demonstrated that $S$. agalactiae from bovine mastitis in China are resistant to many of the antimicrobial compounds commonly used for treatment of mastitis. Resistance to erythromycin was attributed to the genes ermA $(P<0.05)$ and resistance to tetracycline was attributed to the genes tet $K$, tet $M$, tet $O(P<0.01)$. In addition, the results indicated that the virulence genes $c y l, c f b, h y l B$ were preponderant virulence genes in $S$. agalactiae. 
Z. Zhang, F. Yang, X. Li, et al. 2019. Distribution of Serotypes, Antimicrobial Resistance and Virulence Genes among Streptococcus agalactiae Isolated from Bovine in China. Acta Scientiae Veterinariae. 47: 1699.

MANUFACTURERS

${ }^{1}$ Guangzhou Detgerm Microbiology Technology Co. Ltd. Guangzhou, China.

${ }^{2}$ Omega Bio-Tek. Norcross, GA, USA.

${ }^{3}$ Takara Bio. Dalian, China.

${ }^{4} \mathrm{HKM}$. Guangzhou, China.

Funding. This research is supported by The National Key Re- search and Development Program of China (2017YFD0502200), International Science and Technology Cooperation Project of Gansu Province, China (17YF1WA169), the Agricultural Science and Technology Innovation Program (CAAS-ASTIP2014-LIHPS-03) and Chinese Academy of Agricultural Sciences Basal Research Fund (Y2016PT43).

Declaration of interest. The authors report no conflict interest. The authors alone are responsible for the content and writing of paper.

\section{REFERENCES}

1 Alkasir R., Wang J., Gao J., Ali T., Zhang L., Szenci O., Bajcsy Á.C. \& Han B. 2016. Properties and antimicrobial susceptibility of Trueperella pyogenes isolated from bovine mastitis in China. Acta Veterinaria Hungarica. 64(1): 1-12.

2 Arana D.M., Rojobezares B., Torres C. \& Alós J.I. 2014. First clinical isolate in europe of Clindamycin-resistant Group B Streptococcus mediated by the lnu(b) gene. Revista Espanola de Quimioterapia. 27(2): 106-109.

3 Beckmann C., Waggoner J.D., Harris T.O., Tamura G.S. \& Rubens C.E. 2002. Identification of Novel Adhesins From Group B Streptococci by use of phage display reveals that c5a peptidase mediates fibronectin binding. Infection \& Immunity. 70(6): 2869-2876.

4 Bergal A., Loucif L., Benouareth D.E., Bentorki A.A., Abat C. \& Rolain J.M. 2015. Molecular epidemiology and distribution of serotypes, genotypes, and antibiotic resistance genes of Streptococcus agalactiae clinical isolates from Guelma, Algeria and Marseille, France. European Journal of Clinical Microbiology \& Infectious Diseases. 34(12): 2339-2348.

5 Blowey R., Edmondson P., Blowey R. \& Edmondson P. 2010. Mastitis Control in Dairy Herds. 2nd edn. Wallingford: CABI, pp.25-40.

6 Cha E., Kristensen A.R., Hertl J.A., Schukken Y.H., Tauer L.W., Welcome F.L. \& Gröhn Y.T. 2014. Optimal insemination and replacement decisions to minimize the cost of pathogen-specific clinical mastitis in dairy cows. Journal of Dairy Science. 97(4): 2101-2117.

7 Ding Y., Zhao J., He X., Li M., Guan H., Zhang Z. \& Li P. 2015. Antimicrobial resistance and virulence-related genes of Streptococcus obtained from dairy cows with mastitis in Inner Mongolia, China. Pharmaceutical Biology. 54(1): 1-6.

8 Duarte R.S., Miranda O.P., Bellei B.C., Brito M.A. \& Teixeira L.M. 2004. Phenotypic and molecular characteristics of Streptococcus agalactiae isolates recovered from milk of dairy cows in Brazil. Journal of Clinical Microbiology. 42(9): 22-4214.

9 Ebrahimi A., Moatamedi A., Lotfalian S. \& Mirshokraei P. 2013. Biofilm formation, hemolysin production and antimicrobial susceptibilities of Streptococcus agalactiae isolated from the mastitis milk of dairy cows in shahrekord district, Iran. Veterinary Research Forum. 4(4): 269-272.

10 Emaneini M., Khoramian B., Jabalameli F., Abani S., Dabiri H. \& Beigverdi R. 2016. Comparison of virulence factors and capsular types of Streptococcus agalactiae isolated from human and bovine infections. Microbial Pathogenesis. 91(22): 1-4.

11 Entorf M., Feßler A.T., Kaspar H., Kadlec K., Peters T. \& Schwarz S. 2016. Comparative erythromycin and tylosin susceptibility testing of streptococci from bovine mastitis. Veterinary Microbiology. 194: 36-42.

12 Erskine R.J., Walker R.D., Bolin C.A., Bartlett P.C. \& White D.G. 2002. Trends in antibacterial susceptibility of mastitis pathogens during a seven-year period. Journal of Dairy Science. 85(5): 1111-1118.

13 Eskandarian N., Ismail Z., Neela V., Van B.A., Desa M.N. \& Amin N.S. 2015. Antimicrobial susceptibility profiles, serotype distribution and virulence determinants among invasive, non-invasive and Colonizing Streptococcus agalactiae (group B Streptococcus) from malaysian patients. European Journal of Clinical Microbiology \& Infectious Diseases. 34(3): 579-584.

14 Ferguson J.D., Azzaro G., Gambina M. \& Licitra G. 2007. Prevalence of Mastitis Pathogens in Ragusa, Sicily, from 2000 to 2006. Journal of Dairy Science. 90(12): 5798-5813.

15 Feßler A.T., Kaspar H., Lindeman C.J., Stegemann M.R., Peters T., Mankertz J., Watts J.L. \& Schwarz S. 2012. A proposal of interpretive criteria for cefoperazone applicable to bovine mastitis pathogens. Veterinary Microbiology. 157(12): 226-231.

16 Guerrero-Ramos E., Cordero J., Molina-González D., Poeta P., Igrejas G., Alonso-Calleja C. \& Capita R. 2016. Antimicrobial resistance and virulence genes in enterococci from wild game meat in Spain. Food Microbiology. 53: 156-164.

17 Huijps K., Lam T.J. \& Hogeveen H. 2008. Costs of mastitis: facts and perception. Journal of Dairy Research. 75(1): 113-120.

18 Imperi M., Pataracchia M., Alfarone G., Baldassarri L., Orefici G. \& Creti R. 2010. A multiplex pcr assay for the direct identification of the capsular type (ia to Ix) of Streptococcus agalactiae. Journal of Microbiological Methods. 80(2): 212-214. 
19 Jain B., Tewari A., Bhandari B.B. \& Jhala M.K. 2012. Antibiotic resistance and virulence genes in Streptococcus agalactiae isolated from cases of bovine subclinical mastitis. Veterinarski Arhiv. 82: 423-432.

20 Kalmus P., Orro T. \& Kask K. 2011. Udder pathogens and their resistance to antimicrobial agents in dairy cows in Estonia. Acta Veterinaria Scandinavica. 53(1): 1-7.

21 Katholm J., Bennedsgaard T.W., Koskinen M.T. \& Rattenborg E. 2012. Quality of bulk tank milk samples from danish dairy herds based on Real-time Polymerase Chain Reaction identification of mastitis pathogens. Journal of Dairy Science. 95(10): 5702-5708.

22 Keefe G.P. 1997. Streptococcus agalactiae mastitis: a review. Canadian Veterinary Journal. 38(7): 429-437.

23 Keefe G. 2012. Update on Control of Staphylococcus aureus and Streptococcus agalactiae for Management of Mastitis. Veterinary Clinics of North America: Food Animal Practice. 28(2): 203-216.

24 Lindeman C.J., Portis E., Johansen L., Mullins L.M. \& Stoltman G.A. 2013. Susceptibility to antimicrobial agents among bovine mastitis pathogens isolated from north American dairy cattle, 2002-2010. Journal of Veterinary Diagnostic Investigation. 25(5): 581-591.

25 Nam H.M., Lim S.K., Kang H.M., Kim J.M., Moon J.S., Jang K.C., Joo Y.S., Kang M.I. \& Jung S.C. 2010. Antimicrobial Resistance of Enterococci Isolated from Mastitic Bovine Milk Samples in Korea. Zoonoses \& Public Health. 21(5): 698-701.

26 Olde-riekerink R.G., Barkema H.W., Veenstra S., Poole D.E., Dingwell R.T. \& Keefe G.P. 2006. Prevalence of contagious mastitis pathogens in bulk tank milk in Prince Edward Island. Canadian Veterinary Journal. 47(6): 567-572.

27 Pereira U.P., Mian G.F., Oliveira I.C.M., Benchetrit L.C., Costa G.M. \& Figueiredo H.C.P. 2010. Genotyping of Streptococcus agalactiae strains isolated from fish, human and cattle and their virulence potential in Nile Tilapia. Veterinary Microbiology. 140(2): 186-192.

28 Pinto T.C., Costa N.S., Vianna souza A.R., Silva L.G., Corrêa A.B., Fernandes F.G., Oliveira I.C., Mattos M.C., Rosado A.S. \& Benchetrit L.C. 2013. Distribution of serotypes and evaluation of antimicrobial susceptibility among human and bovine Streptococcus agalactiae strains isolated in Brazil Between 1980 and 2006. Brazilian Journal of Infectious Diseases. 17(2): 131-136.

29 Pitkälä A., Haveri M., Pyörälä S., Myllys V. \& Honkanenbuzalski T. 2004. Bovine mastitis in Finland 2001- prevalence, distribution of bacteria, and antimicrobial resistance. Journal of Dairy Science. 87(8): 2433-2441.

30 Radtke A., Bruheim T., Afset J.E. \& Bergh K. 2012. Multiple-locus variant-repeat assay (mlva) is a useful tool for molecular epidemiologic analysis of Streptococcus agalactiae strains causing bovine mastitis. Veterinary Microbiology. 157(4): 398-404.

31 Rato M.G., Bexiga R., Florindo C., Cavaco L.M., Vilela C.L. \& Santos-Sanches I. 2013. Antimicrobial resistance and molecular epidemiology of streptococci from bovine mastitis. Veterinary Microbiology. 161(3): 286-294.

32 Salvador R.T., Beltran J.M.C., Abes N.S., Gutierrez C.A. \& Mingala C.N. 2012. Prevalence and risk factors of subclinical mastitis as determined by the California Mastitis Test in water buffaloes (Bubalis bubalis) in Nueva Ecija, Philippines. Journal of Dairy Science. 95(3): 1363-1366.

33 Shome B.R., Bhuvana M., Mitra S.D., Krithiga N., Shome R., Velu D., Banerjee A., Barbuddhe S.B., Prabhudas K. \& Rahman H. 2012. Molecular characterization of Streptococcus agalactiae and Streptococcus uberis isolates from bovine milk. Tropical Animal Health \& Production. 44(8): 1981-1992.

34 Tenhagen B.A., Köster G., Wallmann J. \& Heuwieser W. 2006. Prevalence of mastitis pathogens and their resistance against antimicrobial agents in dairy cows in Brandenburg, Germany. Journal of Dairy Science. 89(7): 2542-2551.

35 Yang Y., Liu Y., Ding Y., Yi L., Ma Z., Fan H. \& Lu C. 2013. Molecular characterization of Streptococcus agalactiae isolated from bovine mastitis in Eastern China. Plos One. 8(7): 67755-67786.

36 Zhang Z., Li X.P., Yang F., Luo J.Y., Wang X.R., Liu L.H. \& Li H.S. 2016. Influences of season, parity, lactation, udder area, milk yield, and clinical symptoms on intramammary infection in dairy cows. Journal of Dairy Science. 99(8): 6484-6493.

37 Zhao Z., Kong F., Martinez G., Zeng X., Gottschalk M. \& Gilbert G.L. 2010. Molecular serotype identification of Streptococcus agalactiae of bovine origin by multiplex pcr-based reverse line blot hybridization assay. FEMS Microbiology Letters. 263(2): 236-239. 